\title{
Changes in the length and area of congenital nevi involving the face and extremities after two serial excisions
}

\section{Jae Il Choi ${ }^{1}$, Daegu Son ${ }^{2}$}

${ }^{1}$ Cheongdam Style Aesthetic Plastic Surgery Clinic, Daegu; ${ }^{2}$ Department of Plastic and Reconstructive Surgery, Keimyung University School of Medicine, Daegu, Korea
This article is a part of Jae Il Choi master's thesis at Keimyung University Graduate School.
Background The objective of this study was to determine the outcome of serial excisions of congenital nevi involving the face and extremities and to calculate changes in the area and length of the nevi.

Methods Data from 18 patients with congenital nevi who underwent serial excisions from 2005 to 2017 were retrospectively reviewed. There were 12 congenital nevi involving the face and six involving the extremities. Two serial excisions were performed in all cases. The final diagnosis was confirmed by histology. Postoperative outcomes were analyzed photogrammetrically. The clinical outcomes were analyzed through ordinary scales.

Results The mean age of patients and the median area, length, and width of congenital nevi on the face and extremities were 9.4 and 15.2 years, 189.8 and $487.8 \mathrm{~mm}^{2}, 21.1$ and $35.0 \mathrm{~mm}$, and 13.2 and $19.6 \mathrm{~mm}$, respectively. After the first operation, photogrammetric analysis showed a $64.6 \%$ reduction in the area of facial nevi and a $68.1 \%$ reduction for nevi on the extremities. The final scar length increased by $62.8 \%$ for the face and $73 \%$ for the extremities compared to before surgery. A clinical assessment demonstrated excellent results for the removal of the congenital nevi, without any deformation of the surrounding structures, and good final scar quality.

Conclusions This study will contribute to the prediction of results of each stage when serial excision is required.

Keywords Nevus / Surgical wound / Surgical flaps / Nevus, intradermal

\section{INTRODUCTION}

Serial excision or staged excision is a well-established method in plastic surgery. It is widely used to remove congenital nevi, wide scars, and confined tattoos. The technique itself is very simple be-

Received: Sep 29, 2020 Revised: Nov 10, 2020 Accepted: Dec 14, 2020 Correspondence: Daegu Son Department of Plastic and Reconstructive Surgery, Institute for Medical Science, Keimyung University School of Medicine, 1095 Dalgubeol-daero, Dalseo-gu, Daegu 42601, Korea Tel: +82-53-258-7817, Fax: +82-53-258-4590, E-mail: handson@dsmc.or.kr Copyright @ 2021 The Korean Society for Aesthetic Plastic Surgery.

This is an Open Access article distributed under the terms of the Creative Commons Attribution Non-Commercial License (https://creativecommons.org/licenses/by-nc/4.0/) which permits unrestricted non-commercial use, distribution, and reproduction in any medium, provided the original work is properly cited. www.e-aaps.org cause it only involves excision and suturing. However, the operator must decide how many resections to perform, how much tissue to excise during the first resection, and which shape is appropriate.

The most commonly used excision method is elliptical or fusiform excision. The length of this shape of resection should be 3-4.5 times its width to obtain good results without leaving a dog ear [14]. Reducing this ratio as much as possible is the goal of staged resection. However, it is difficult to predict the final length after staged resection. Accurate descriptions of this issue in textbooks are difficult to find, and most studies have only dealt with length. Changes in area have not been published yet. In addition, the results of geometric studies cannot be directly applied to patients in clinical practice [5]. Factors affecting the number of stages of resection and the final length include lesion size and shape, anatomical location, and the elasticity of surrounding tissues [6]. 
The purpose of this study was to examine changes in the final length and area of congenital nevi on the face and extremities after two consecutive resections. Finding a way to accurately measure area is also an important part of this study. The scope of the study was restricted to two consecutive resections in patients with the same diagnosis to exclude other causes affecting the length of the scar.

\section{METHODS}

This retrospective study received approval from the Institutional Review Board of Keimyung University Dongsan Hospital (IRB No. 2017-09-046). A group of patients with congenital nevi of the face or extremities who underwent staged resection surgery from February 2005 to September 2017 at Keimyung University Dongsan Hospital were selected. The study subjects were limited to patients in whom congenital nevi were completely resected after two consecutive resections. Twelve patients with facial nevi and six patients with nevi of the extremities were included. Congenital nevi were diagnosed based on histological examinations.

\section{Surgical methods}

Surgery was performed under general anesthesia in patients younger than 10 years of age and under local anesthesia for those aged more than 10 years. In the first surgery, the resection was designed elliptically, with the goal of resecting $70 \%-80 \%$ of the lesion. After injecting $1 \%$ lidocaine containing 1:100,000 epinephrine into the area, an incision was made with a surgical knife and excision was performed with some subcutaneous fat using Metzenbaum scissors. In the initial surgery, undermining of the subcutaneous layer was not performed to avoid scarring at the surgical site. The subcutaneous layer was sutured using 4-0 or 5-0 Monosyn or white nylon, and 5-0 or 6-0 nylon was used to suture the skin. The tissue from the first operation was delivered to the pathology department for diagnosis. The second operation was performed at least 6 months after the first operation. The second excision used an elliptical, fusiform, or W-plasty design, and completely included the remaining lesion. To minimize the length of the incision, the angle formed by the two incision lines at both ends was close to $50^{\circ}$, which is larger than the normal angle of $30^{\circ}$ [7]. Resection was performed in the same manner as in the first surgery. To minimize scarring, undermining of the subcutaneous layer was performed to ensure a tension-free primary suture. When deformation was observed in surrounding structures such as the eyes, nose, and face, it was minimized by fixing one flap away from the structure to the periosteum. In order to fix the non-absorbable suture to the periosteum, dissection was not performed. A location was selected with relatively little nerve and blood vessel distribution. When a 4-0 nylon needle touched the periosteum by vertical stabbing, it snatched the periosteum with the feeling of biting the bone. The feeling of suffi- cient resistance when pulling the suture confirmed that the suture was properly fixed to the periosteum. It then became easier to make the needle of the suture into a fishing needle shape. Subcutaneous fat was appropriately excised at both ends to reduce dog ears. Suturing was performed in the same manner as in the first surgery. The patient and/or the patient's guardian was given instructions on how to apply Steri-Strips thoroughly for 3 months after surgery (Fig. 1). The same procedure was used when performing surgery on the extremities, but surgical undermining was performed in the suprafascial plane.

\section{Chart review}

From the medical records and clinical pictures of the 18 patients, information was collected on the patients' age, medical and surgical history, length and width of the original nevus, area, short axisto-long axis ratio ( $\mathrm{S} / \mathrm{L}$ ratio), complications during follow-up, pathologic diagnosis, change in size of the nevus after the first surgery, and length of the final scar.

\section{Image analysis}

All measurements were made using ImageJ software (National Institutes of Health, Bethesda, MD, USA; http://rsb.info.nih.gov/ij/ download.html). The measurement method is briefly described as follows. First, the image file to be measured was imported into ImageJ. A scale range was then set for the measurer in the photo. The actual measurement units $(\mathrm{mm}, \mathrm{cm})$ were then entered in "Analyze/Set Scale." The nevus to be measured was outlined with a brush. The image type was changed to 8-bit (Fig. 2A and B). The bar in "Image/Adjust/Threshold" was adjusted to erase all images except the contour (Fig. 2C and D). When the magic wand icon was pressed, a yellow line appeared inside the contour and the area was measured with "Analyze/Measure" (Fig. 2E and F). The long axis and short axis to be measured were displayed with a line. Its length was measured with "Analyze/Measure" (Fig. 2G and H).

\section{Clinical analysis}

Postoperative outcomes were evaluated with ordinal scales. The evaluators were chosen to exclude those who could have a subjective opinion and those who participated in the surgery. The evaluators consisted of six people who could make objective evaluations, including one plastic surgeon, one plastic resident, one surgeon from another department, one member of the general public, and two nurses. Using photographs taken before and after surgery, each evaluator evaluated the following parameters using the ordinal scale method: (1) the completeness of nevus removal, (2) the degree of scarring, (3) the degree of deformation (of major structures such as the eyes, nose, and mouth for nevi in the facial area or of tissue deformation for nevi in the extremities). For each item, the highest score was 5 points and the lowest score was 1 point. The total score was used to determine the following four categories of 

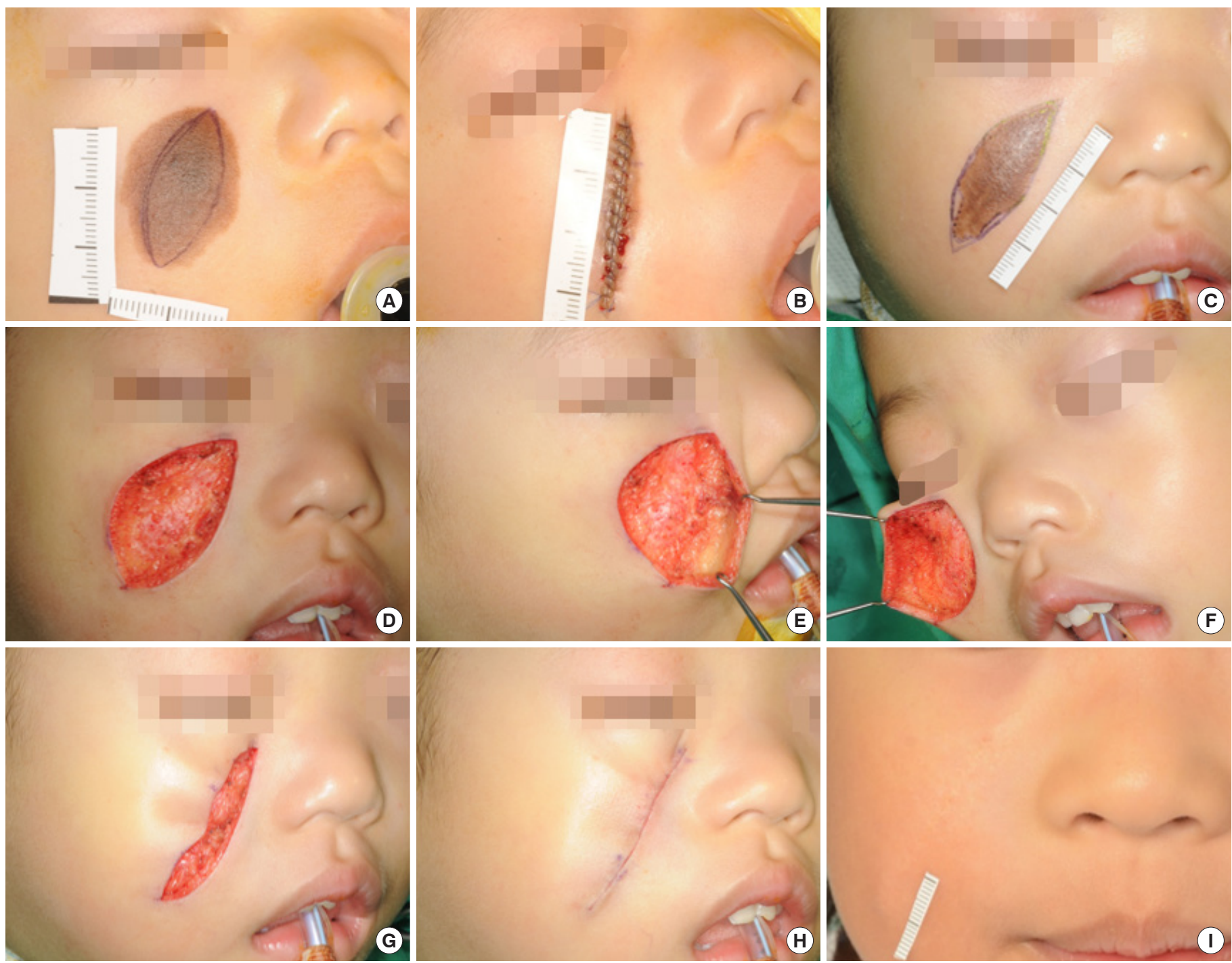

Fig. 1. The lesion was in a position that could affect major structures of the face, eyes, nose, and mouth. (A) Design of the first-stage operation, (B) immediately after the first excision, (C) 12 months after the first-stage excision and design of the second-stage operation, (D) after complete excision, (E, F) after sufficiently undermining the subcutaneous fat layer on both sides. (G) When the subcutaneous layer of the lateral flap was fixed to the periosteum, $(\mathrm{H})$ the medial flap could be sutured to the lateral flap without tension. This allowed the operator to primarily close the defect so that the nose and mouth were not pulled outward. (I) Postoperative view at 3 years.

outcomes: excellent (25-30 points), good (19-24 points), fair (1318 points), and poor (less than 12 points).

\section{Statistical analysis}

The distribution of patients by sex was expressed as a percentage, and age was expressed as the mean and standard deviation. Area, length, and the S/L ratio were expressed as median and interquartile range, and skewness and kurtosis were analyzed for the surgical site and number of operations. The mean and standard deviation of the amount of change (\%) according to the number of operations were also calculated. To determine the significance of differences in area, length, width, and the $\mathrm{S} / \mathrm{L}$ ratio according to the num- ber of operations, the Wilcoxon signed-rank test (a nonparametric method) was used because the sample was small and the data were asymmetrically distributed. In addition, a box plot was presented so that the amount of change for each measurement could be easily recognized. The independent t-test was used to compare the proportional change for the face and extremities between preoperative and postoperative measurements. For all statistical analyses, $\mathrm{R}$ version 3.6.0 (@2019; The R Foundation for Statistical Computing Platform, Vienna, Austria) was used. The significance level for statistical tests was set to be $5 \%$. A P-value less than 0.05 was interpreted as indicating statistical significance. 


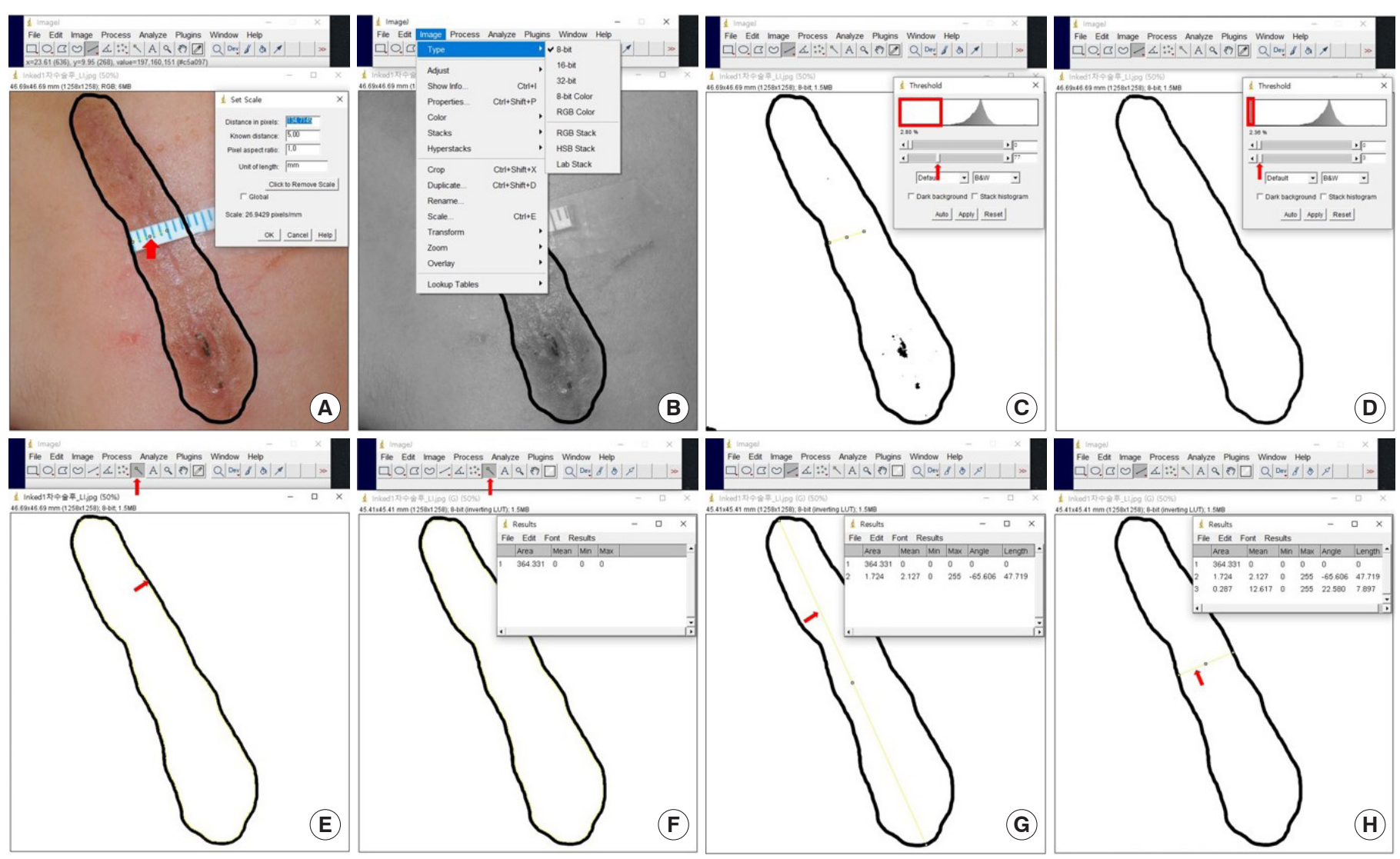

Fig. 2. Measurements using ImageJ software. (A) After selecting the length icon, the ruler in the figure determines the desired range (arrow). In the "Analyze/Set Scale" box, the actual ruler length is entered (5.00) and the units of length are indicated (mm). (B) Converting the "Image/ Type" to 8-bit results in a black and white image. (C, D) Adjusting the bar in "Image/Adjust/Threshold" erases everything in the image except the outline. $(E, F)$ Pressing the magic wand icon causes a yellow line to appear inside the contour, and the area is measured with "Analyze/Measure." $(G, H)$ The long axis and short axis to be measured are displayed with a line and the length is measured with "Analyze/Measure."

Table 1. General characteristics of patients

\begin{tabular}{lc}
\hline Characteristics & Value \\
\hline Face & \\
Sex (male/female) & $6 / 6$ \\
Age (yr) & $9.41 \pm 5.32$ \\
Extremity & \\
Sex (male/female) & $3 / 3$ \\
Age (yr) & $15.17 \pm 7.73$ \\
\hline
\end{tabular}

Values are presented as number or mean \pm SD.

\section{RESULTS}

The mean age of the 12 patients with facial nevi was 9.4 years. The average size, length, and width of the facial nevi were $320.9 \mathrm{~mm}^{2}$, $23.6 \mathrm{~mm}$, and $15.0 \mathrm{~mm}$, respectively. The mean age of the six patients with nevi on the extremities was 15.2 years. The mean size, length, and width of the nevi on the extremities were $677.7 \mathrm{~mm}^{2}$, $39.7 \mathrm{~mm}$, and $21.1 \mathrm{~mm}$, respectively. The median area, length, and
Table 2. Preoperative measurements of the nevi

\begin{tabular}{lcccc}
\hline Variable & Mean \pm SD & Median (IQR) & Skewness & Kurtosis \\
\hline Face $(\mathrm{n}=12)$ & & & & \\
Area $\left(\mathrm{mm}^{2}\right)$ & $320.9 \pm 329.3$ & $189.8(189.8)$ & 1.79 & 2.14 \\
Length $(\mathrm{L}, \mathrm{mm})$ & $23.6 \pm 11.3$ & $21.1(9.6)$ & 1.25 & 1.09 \\
Width $(\mathrm{S}, \mathrm{mm})$ & $15.0 \pm 6.8$ & $13.2(6.5)$ & 1.27 & 0.74 \\
S/L ratio & $0.651 \pm 0.123$ & $0.627(0.110)$ & 1.43 & 2.12 \\
Extremity $(\mathrm{n}=6)$ & & & & \\
Area $\left(\mathrm{mm}^{2}\right)$ & $677.7 \pm 649.0$ & $487.8(626.1)$ & 1.63 & 2.83 \\
Length $(\mathrm{L}, \mathrm{mm})$ & $39.7 \pm 24.9$ & $35.0(27.1)$ & 1.07 & 1.21 \\
Width $(\mathrm{S}, \mathrm{mm})$ & $21.1 \pm 6.9$ & $19.6(10.8)$ & 0.19 & -1.00 \\
S/L ratio & $0.638 \pm 0.226$ & $0.687(0.374)$ & -0.15 & -1.08 \\
\hline
\end{tabular}

$I Q R$, interquartile range.

width of the facial nevi were $189.8 \mathrm{~mm}^{2}, 21.1 \mathrm{~mm}$, and $13.2 \mathrm{~mm}$, respectively. The median size, length, and width of the nevi on the extremities were $487.8 \mathrm{~mm}^{2}, 35.0 \mathrm{~mm}$, and $19.6 \mathrm{~mm}$, respectively.

Both skewness and kurtosis in the facial area were found to be 
Table 3. Image analysis of the proportional change between the preoperative status and the first-stage operation

\begin{tabular}{|c|c|c|c|c|}
\hline Variable & $\begin{array}{l}\text { Proportional } \\
\text { change (\%) } \\
\text { (preoperative } \\
\text { to after the first- } \\
\text { stage operation) }\end{array}$ & $\begin{array}{c}\text { Pre- } \\
\text { operative }\end{array}$ & $\begin{array}{c}\text { After } \\
\text { first-stage } \\
\text { operation }\end{array}$ & P-value \\
\hline \multicolumn{5}{|l|}{ Face $(n=12)$} \\
\hline Area $\left(\mathrm{mm}^{2}\right)$ & $-35.4 \pm 16.1$ & $189.8(189.8)$ & 120.4 (148.7) & $<0.001$ \\
\hline Length (L, mm) & $17.3 \pm 9.3$ & $21.1(9.6)$ & $24.6(11.1)$ & $<0.001$ \\
\hline Width (S, mm) & $-41.8 \pm 14.4$ & $13.2(6.5)$ & $7.5(3.7)$ & $<0.001$ \\
\hline $\mathrm{S} / \mathrm{L}$ ratio & $-50.4 \pm 11.8$ & $0.627(0.110)$ & $0.315(0.128)$ & $<0.001$ \\
\hline \multicolumn{5}{|l|}{ Extremity $(n=6)$} \\
\hline Area $\left(\mathrm{mm}^{2}\right)$ & $-31.9 \pm 11.8$ & $487.8(626.1)$ & 385.9 (364.9) & 0.031 \\
\hline Length (L, mm) & $21.6 \pm 20.9$ & $35.0(27.1)$ & $38.5(26.7)$ & 0.063 \\
\hline Width $(\mathrm{S}, \mathrm{mm})$ & $-42.0 \pm 14.7$ & $19.6(10.8)$ & $13.4(8.0)$ & 0.031 \\
\hline $\mathrm{S} / \mathrm{L}$ ratio & $-50.3 \pm 16.1$ & $0.687(0.374)$ & 0.270 (0.218) & 0.031 \\
\hline
\end{tabular}

Values are presented as mean \pm SD or median (interquartile range).

$\mathrm{P}$-value from the Wilcoxon signed-rank test.

Table 4. Image analysis of the proportional change between the first- and second-stage operations

\begin{tabular}{|c|c|c|c|c|}
\hline Variable & $\begin{array}{l}\text { Proportional } \\
\text { change (\%) } \\
\text { (first-stage to } \\
\text { second-stage } \\
\text { operation) }\end{array}$ & $\begin{array}{c}\text { After } \\
\text { first-stage } \\
\text { operation }\end{array}$ & $\begin{array}{c}\text { After } \\
\text { second-stage } \\
\text { operation }\end{array}$ & $P$-value \\
\hline \multicolumn{5}{|l|}{ Face $(n=12)$} \\
\hline Area $\left(\mathrm{mm}^{2}\right)$ & $-100 \pm N A$ & $120.4(148.7)$ & 0 (NA) & $<0.001$ \\
\hline Length ( $\mathrm{L}, \mathrm{mm})$ & $39.0 \pm 17.1$ & $24.6(11.1)$ & 33.2 (13.5) & $<0.001$ \\
\hline Width $(\mathrm{S}, \mathrm{mm})$ & $-100 \pm N A$ & 7.5 (3.7) & 0 (NA) & $<0.001$ \\
\hline $\mathrm{S} / \mathrm{L}$ ratio & $-100 \pm N A$ & 0.315 (0.128) & 0 (NA) & $<0.001$ \\
\hline \multicolumn{5}{|l|}{ Extremity $(n=6)$} \\
\hline Area $\left(\mathrm{mm}^{2}\right)$ & $-100 \pm N A$ & 385.9 (364.9) & $0(N A)$ & 0.031 \\
\hline Length ( $\mathrm{L}, \mathrm{mm})$ & $41.4 \pm 19.4$ & $38.5(26.7)$ & $56.9(24.4)$ & 0.031 \\
\hline Width (S, mm) & $-100 \pm N A$ & $13.4(8.0)$ & $0(N A)$ & 0.031 \\
\hline$S / L$ ratio & $-100 \pm N A$ & $0.270(0.218)$ & $0(N A)$ & 0.031 \\
\hline
\end{tabular}

Values are presented as mean \pm SD or median (interquartile range). $N A$, standard deviation could not be calculated because all observations were equal. P-value from the Wilcoxon signed-rank test.

concentrated on the left side and around the mean, with an average of more than 0 . For the extremities, the kurtosis of width and the S/L ratio and the skewness of the $\mathrm{S} / \mathrm{L}$ ratio were less than 0 . The width of the nevi deviated from the average to a greater extent than the length of the nevi (Tables 1,2). The interval between the first and second surgical procedures was 10.7 months on average for both categories of nevi.
Table 5. Image analysis of the proportional change between the preoperative status and the second-stage operation

\begin{tabular}{|c|c|c|c|c|}
\hline Variable & $\begin{array}{l}\text { Proportional } \\
\text { change (\%) } \\
\text { [preoperative to } \\
\text { second-stage } \\
\text { operation) }\end{array}$ & $\begin{array}{c}\text { Pre- } \\
\text { operative }\end{array}$ & $\begin{array}{c}\text { After } \\
\text { second- } \\
\text { stage } \\
\text { operation }\end{array}$ & P-value \\
\hline \multicolumn{5}{|l|}{ Face $(n=12)$} \\
\hline Area $\left(\mathrm{mm}^{2}\right)$ & $-100.0 \pm N A$ & 189.8 (189.8) & 0 (NA) & 0.001 \\
\hline Length (L, mm) & $62.8 \pm 22.9$ & $21.1(9.6)$ & $33.2(13.5)$ & 0.001 \\
\hline Width $(\mathrm{S}, \mathrm{mm})$ & $-100.0 \pm N A$ & $13.2(6.5)$ & 0 (NA) & 0.001 \\
\hline$S / L$ ratio & $-100.0 \pm N A$ & $0.627(0.110)$ & 0 (NA) & 0.001 \\
\hline \multicolumn{5}{|l|}{ Extremity $(n=6)$} \\
\hline Area $\left(\mathrm{mm}^{2}\right)$ & $-100.0 \pm N A$ & $487.8(626.1)$ & 0 (NA) & 0.031 \\
\hline Length (L, mm) & $73.1 \pm 45.0$ & $35.0(27.1)$ & $56.9(24.4)$ & 0.031 \\
\hline Width (S, mm) & $-100.0 \pm N A$ & $19.6(10.8)$ & 0 (NA) & 0.031 \\
\hline$S / L$ ratio & $-100.0 \pm N A$ & $0.687(0.374)$ & 0 (NA) & 0.031 \\
\hline
\end{tabular}

Values are presented as mean \pm SD or median (interquartile range). $N A$, standard deviation could not be calculated because all observations were equal. P-value from the Wilcoxon signed-rank test.
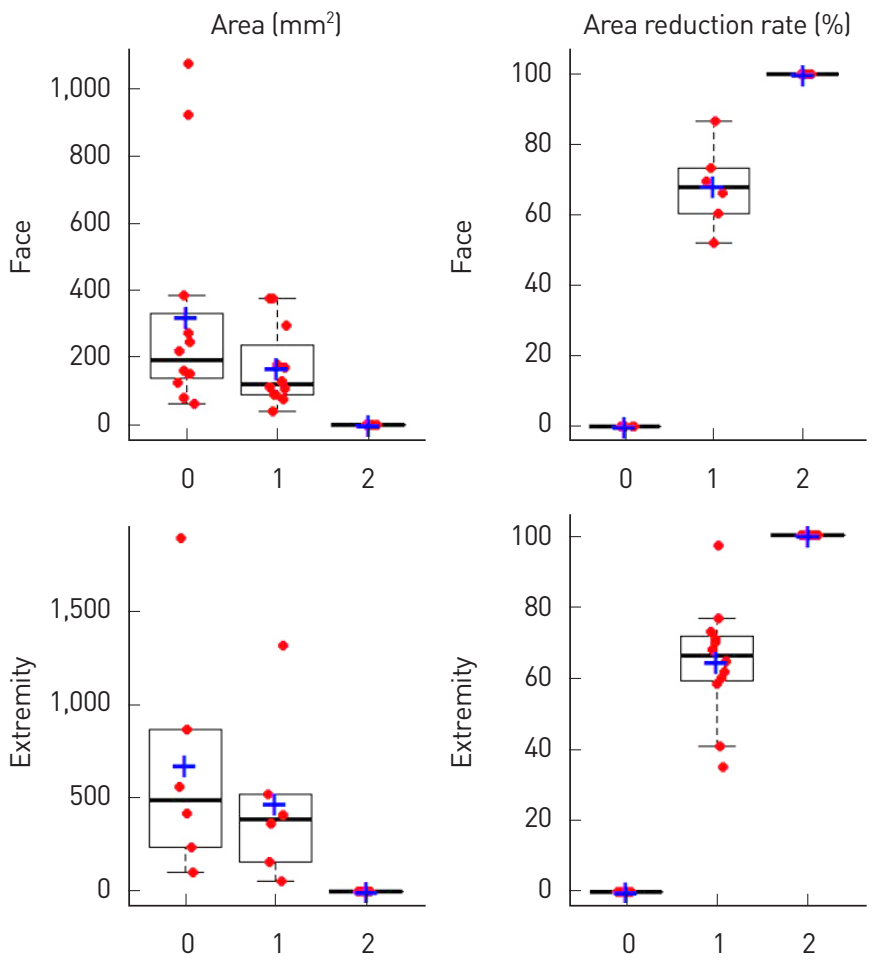

Fig. 3. Area and area reduction rate according to the number of operations (+: average).

\section{Image analysis}

After the first-stage operation, the area of the facial nevi decreased by $64.6 \%$ on average and the width decreased by $58.2 \%$, while the length increased by $17.3 \%$. The $\mathrm{S} / \mathrm{L}$ ratio decreased from 0.63 to 

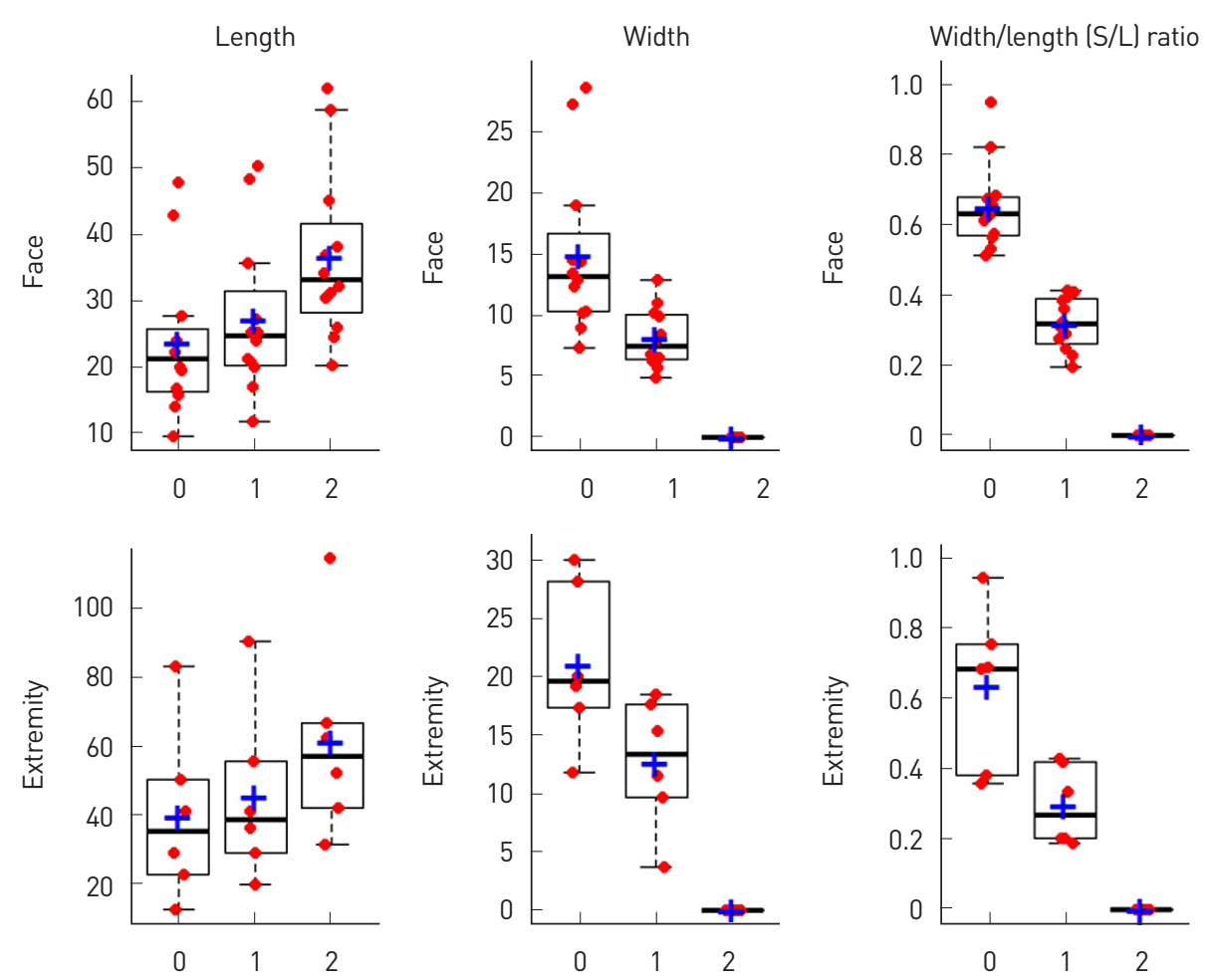

Fig. 4. Length, width, and width/length ratio (S/L ratio) according to the number of operations (+: average).

0.32. For the extremities, the area decreased by an average of $68.1 \%$ and the width decreased by $58.0 \%$, while the length increased by $21.6 \%$. The S/L ratio decreased from 0.69 to 0.27 (Table 3).

Relative to the first surgery, after the second-stage operation, the length increased by $39.0 \%$ in the facial area and $41.4 \%$ in the extremities. The nevi were completely excised, so the area was $0 \mathrm{~mm}^{2}$; instead, only a line was left (Table 4). Compared to the preoperative values, the scar length increased by $62.8 \%$ in the face and by $73 \%$ in the extremities (Table 5).

A box plot was made to demonstrate the amount of change for each measurement in an accessible format. The area and proportional area reduction according to the number of operations are shown in Fig. 3. Changes in length, width, and the S/L ratio according to the number of operations are shown in Fig. 4.

\section{Clinical analysis}

In the clinical evaluation, the degree of completeness of removal of the facial nevi was excellent (mean, 29.5 points), the degree of scarring was good (mean, 22.33 points), and the degree of deformation of major structures was excellent (mean, 26.75 points). For nevi on the extremities, the degree of completeness of removal was excellent (mean, 30 points), the degree of scarring was good (mean, 22.33 points), and the degree of tissue deformation was excellent (mean, 25 points). The clinical assessments were equivalent for the face and extremities. In other words, the nevi were completely removed (with excellent outcomes) without deformation of the surrounding structures or tissues, although the resulting scars were evaluated as good.

\section{DISCUSSION}

In the first operation for staged excision, the area of the nevi decreased by $64.6 \%$ for the face and $68.1 \%$ for the extremities, while the length of the final scar after the second operation increased by $62.8 \%$ for the face and $73 \%$ for extremities. The clinical evaluations showed that the lesions were completely excised without deformation of the surrounding structures, and favorable outcomes were also reported for the degree of scarring. This is a very good result, considering that the length of the scar has been reported to be 3 to 4.5 times the width after a single excision, without a staged resection.

In the literature on this topic, the terms "elliptical" and "fusiform" resection are used interchangeably, which may cause confusion. However, examining the content of the studies on this topic demonstrates that these terms are both used to denote the same shape.

In the study of Tilleman et al. [5], when results were analyzed according to geometric principles, the rhomboid and mosque shapes had the lowest loss of normal skin. Conversely, the fusiform circle and fusiform ellipse had the greatest loss. When geometrically analyzing results, the vertex angle should be $30^{\circ}$ or less in order to keep the length-to-width ratio below 4 in clinical practice. For a rhomboid or S-type shape, a narrow angle of about $30^{\circ}$ is used. However, 
the most common angle used with fusiform and ellipse shapes is much larger than $30^{\circ}$ (almost $60^{\circ}$ ).

If surgery were to be performed using a rhomboid or mosque shape based on the results of a geometric analysis, there would be concerns regarding tissue deformation. Thus, these shapes are not utilized in clinical practice. Staged excision is necessary to reduce the loss of normal skin and to minimize the remaining surgical scar.

Another study of Tilleman et al. [8] mentioned area for the first time. However, their study was not about changes in the area of the lesion itself, but about how much normal tissue was wasted after resection. They reported that the loss of normal tissue was on average about $130 \%$ of the lesion area [8]. According to results of the present study, after resection of about $70 \%$ of the lesions in the first surgery, the $\mathrm{S} / \mathrm{L}$ ratio was about 0.3 . All of the lesions could be completely resected with two resections.

Several variations of staged excision have been introduced. Among them, the "doughnut" method, which involves central excision with purse-string closure using a compressed design, has the goal of resecting the lesion as much as possible and reducing the length of the $\mathrm{X}$ - and $\mathrm{Y}$-axes at the same time during primary surgery. The geometric principle seems to be able to achieve this goal. However, an important point to consider in step-by-step ablation is that one must achieve complete wound healing at each step. A problem with the above method is that it is difficult to obtain complete wound healing after surgery because the suture is very long, which causes significant tissue deformation [9].

In the "cake flap" method, a lesion is divided into four equal parts, and two diagonally-oriented sides are excised first. This method has a relatively simple design, and does not cause tissue deformation. However, it has the disadvantage of being able to excise only $50 \%$ of the lesion in the first excision [10]. Modified S-plasty can be performed to change the axis of a lesion, but the lesion must be relatively large. It is considered to be a favorable option for cases where the length of the remaining scar is limited and a S-shaped scar can be tolerated [11].

The following prerequisites must be met in order to accurately measure the area of a lesion using photography. First, when taking a clinical photograph, in order to avoid distortion of the picture and increase accuracy, the lesion area and the camera lens should be kept parallel. If the lesion is on a curved surface, the camera should be parallel with the lesion area that occupies the largest area. However, deviation from the parallel plane causes some distortion of the periphery. Second, a ruler must be placed in the same frame as the lesion. No matter how good a picture is, it is impossible to set the scale without using a standard for accurate measurement. Third, it is necessary to improve accuracy by using image analysis software.

In two patients, lesions recurred along the surgical scars because pigment cells of the nevus spilled over. The lesions were clearly com- pletely resected during the second-stage operation, and pigmentation was found during follow-up. Therefore, in the first resection, the resection must be performed within the nevus. In the last resection, the nevus must be completely resected, including an approximately 1-mm margin of normal tissue [12].

Although numerous studies have been conducted on staged excision, the lack of accurate measurements for each stage of resection make it difficult to predict and explain the results of surgery. The measurements presented herein are expected to provide practical help for operators in clinical practice.

A limitation of this study is that there were not enough clinical cases. Many patients dropped out because surgery was performed in multiple stages over a long period of time and a clinical photograph was required to obtain accurate measurements every time. We believe that more accurate reference data would be obtained by making measurements of more patients.

This study analyzed changes in the final length and area of lesions after two-stage excision for congenital nevi in the face and extremities. In the first staged excision procedure, the area of the nevi decreased by $64.6 \%$ in the face and $68.1 \%$ in the extremities. The length of the final scar after the second operation increased by $62.8 \%$ in the face and $73 \%$ for extremities. In the clinical evaluation, the lesions were completely excised without deformation of surrounding structures, and the degree of scarring was judged to be good. If staged excision is required, the lack of accurate measurements in the literature for the results of each stage of excision make it difficult to predict and explain the results of surgery. The measurements presented in this study address this gap in the literature and provide practical help for practitioners and patients in clinical settings.

\section{NOTES}

\section{Conflict of interest}

No potential conflict of interest relevant to this article was reported.

\section{Ethical approval}

The study was approved by the Institutional Review Board of Keimyung University Dongsan Hospital (IRB No. 2017-09-046) and performed in accordance with the principles of the Declaration of Helsinki.

\section{Patient consent}

The patient's guardian provided written informed consent for the publication and the use of the patient's images.

\section{ORCID}

Jae Il Choi

Daegu Son

https://orcid.org/0000-0001-8863-5833

https://orcid.org/0000-0002-4653-1048 


\section{REFERENCES}

1. DeHoff PH, Key JE. Application of the finite element analysis to determine forces and stresses in wound closing. J Biomech 1981;14:549-54.

2. Dunlavey E, Leshin B. The simple excision. Dermatol Clin 1998;16:4964.

3. Bennett RG. Complex closures. In: Bennett RG, editor. Fundamentals of cutaneous surgery. St. Louis: Mosby; 1988. p. 473-91.

4. Goldberg LH, Alam M. Elliptical excisions: variations and the eccentric parallelogram. Arch Dermatol 2004;140:176-80.

5. Tilleman TR, Tilleman MM, Krekels GA, et al. Skin waste, vertex angle, and scar length in excisional biopsies: comparing five excision patterns: fusiform ellipse, fusiform circle, rhomboid, mosque, and Sshaped. Plast Reconstr Surg 2004;113:857-61.

6. Quaba O, Shoaib T, Durrani AJ, et al. A user's guide for serial excision. J Plast Reconstr Aesthet Surg 2008;61:712-5.
7. Moody BR, McCarthy JE, Sengelmann RD. The apical angle: a mathematical analysis of the ellipse. Dermatol Surg 2001;27:61-3.

8. Tilleman TR, Neumann MH, Smeets NW, et al. Waste of skin in elliptical excision biopsy of non-melanomatous skin cancer. Scand J Plast Reconstr Surg Hand Surg 2006;40:352-6.

9. Fife DJ, Alam M. Alternative techniques for reduction of scar length during staged excision. J Am Acad Dermatol 2011;65:811-8.

10. Tang L, MacKenzie Ross AD, Nduka C. The cake flap: a new technique for serial excision of benign cutaneous lesions. J Plast Reconstr Aesthet Surg 2011;64:1194-6.

11. Paolo B, Stefania R, Massimiliano C, et al. Modified S-plasty: an alternative to the elliptical excision to reduce the length of suture. Dermatol Surg 2003;29:394-8.

12. Altchek ED. A technical consideration in the serial excision of a nevus. Plast Reconstr Surg 1980;66:849-50. 